\title{
NOVOS ARRANJOS DEMOCRÁTICOS: A RELAÇÃO ENTRE INTERSUBJETIVIDADE E PARTICIPAÇÃo
}

\author{
NEW DEMOCRATIC ARRANGEMENTS: \\ THE RELATIONSHIP BETWEEN INTERSUBJECTIVITY AND PARTICIPATION
}

\author{
José Carlos Kraemer Bortoloti* \\ Neuro José Zambam**
}

\begin{abstract}
Resumo: O objetivo da presente abordagem é afirmar o espaço público como indispensável para a expressão e interação dos indivíduos na formação da cidadania e, assim, compor a democracia no contexto contemporâneo. A garantia de direitos e a sua efetivação no cotidiano da convivência humana são as referências mais elementares e condição para a sua legitimidade. Tradicionalmente, as formas de participação e decisão dependiam exclusivamente de eleições que garantiam a alternância do poder. Esse é um modelo limitado e insuficiente, considerando a complexidade das sociedades hodiernas que pressupõe a existência de uma nova dinâmica. Os conflitos de representação e decisão impulsionam a proposição de novos paradigmas para a interação e efetivação de direitos. Os movimentos sociais, as formas de interação e a expressão da pluralidade existente na sociedade, demandam um modelo de participação intersubjetiva, indicando a cidadania como espaço de interação e vociferação de direitos, especificamente os direitos das culturas, a superação das desigualdades, os novos instrumentos de decisão e as condições efetivas de integração dos povos, ampliando as condições de justiça. Afirmar valores e princípios como a tolerância, a legalidade, a dignidade humana, a sustentabilidade e o compromisso com as futuras gerações, representa a capacidade de evolução da democracia e a necessidade de novos referenciais.
\end{abstract}

Palavras-chave: Democracia. Intersubjetividade. Participação.

Abstract: The objective of this approach is to affirm the public space as essential for the expression and interaction of individuals in the formation of citizenship and thus compose democracy in the contemporary context. The guarantee of rights and its effectiveness in everyday human coexistence are the most basic references and condition for its legitimacy. Traditionally, the forms of participation and decision relied solely of elections that guaranteed the alternation of power. This is a limited and insufficient model considering the complexity of today's society that presupposes the existence of a new dynamic. Conflicts of representation and decision boost to propose new paradigms for interaction and enforcing rights. Social movements, forms of interaction and expression of the existing plurality in society, require a

\footnotetext{
* Doutorando em Direito (UNESA/RJ), com Doutoramento Sanduíche junto à Faculdade de Direito da Universidade de Lisboa financiado pelo PDSE/CAPES. Mestre em Direito (ULBRA/RS). Advogado. Atualmente faz parte do Corpo Docente da Escola de Direito da Faculdade Meridional - IMED, na Coordenação do NUJUR e no NDE do Curso. Pesquisador do Núcleo de Pesquisa Dignidade, Estado e Direito e do Grupo de Pesquisa Direitos Fundamentais e Novos Direitos, ambos do PPGD Stricto Sensu da Universidade Estácio de Sá (UNESA/RJ); membro do Centro de Estudos e Pesquisas em Estado, Jurisdição e Direitos Fundamentais (CEPEJuD) da Escola de Direito da Faculdade Meridional (IMED/RS).

** Pós-doutor em Filosofia (UNISINOS/RS). Doutor em Filosofia (PUC/RS). Mestre em Filosofia (UNISINOS/RS). Atualmente faz parte do Corpo Docente da Escola de Direito da Faculdade Meridional (IMED/RS), na Graduação e no Mestrado em Direito. Pesquisador e Coordenador do grupo de pesquisa Multiculturalismo, minorias, espaço público e sustentabilidade: os impactos da migração na Prática Pedagógica no Ensino Superior. Líder do Grupo de Pesquisa Multiculturalismo e Pluralismo Jurídico. Coordenador do Centro Brasileiro de Pesquisas sobre a Teoria da Justiça de Amartya Sen: interfaces com direito, políticas de desenvolvimento e democracia. Integrante do Grupo de Trabalho: Ética e cidadania da ANPOF - Associação Nacional dos Programas de Pós-Graduação em Filosofia.
} 
model of inter-subjective participation, indicating citizenship as a space for interaction and vociferation rights, specifically the rights of cultures, overcoming inequalities, the new instruments decision and the actual conditions of integration of peoples, expanding the conditions of justice. Affirming values and principles such as tolerance, legality, human dignity, sustainability and commitment to future generations, is the evolution of the capacity of democracy and the need for new standards.

Keywords: Democracy. Intersubjectivity. Participation.

\section{INTRODUÇÃO}

Atualmente se registra a necessidade de fundamentar e atualizar as formas de representação nas sociedades democráticas. Essa reflexão tem como objetivo central apresentar uma abordagem sobre o conflito entre as tradicionais formas de representação social que têm como meta expressar as necessidades, os desejos e as expectativas sociais e as demandas contemporâneas, mais complexas e dinâmicas. Configura-se o conflito entre a problemática terminológico-axiológico tradicional que orientara a estruturação dos espaços democráticos e a necessidade de uma perspectiva de inserção de mecanismos de participação capazes de atualizar o processo democrático segundo o contexto atual e os compromissos com as futuras gerações.

Um processo de participação supõe a formatação de referências e instrumentos deliberativos democráticos com as condições de expressar eficazmente as novas configurações e demandas existentes no interior das sociedades para, então, efetivá-las. A projeção do trabalho se justifica, especificamente, em função das inúmeras deficiências existentes na democracia brasileira que impedem a evolução dos mecanismos de participação e contribuem para a instrumentalização das instituições e do exercício do poder.

A representatividade, além de confusa, adquiriu uma forma simplória que (des)constrói os espaços democráticos e a própria identidade da democracia. Nesse contexto, os instrumentos democráticos mais importantes servem, preferencialmente, aos interesses seletos, corporativos e individualistas. Contraria, dessa forma, a necessidade reconhecida de uma ordem social equitativa, assim como, das referências constitucionais representativas da razão pública.

Essa reflexão não busca inventariar as concepções democráticas e os instrumentos de participação, ou mesmo, interpretar as teorias da justiça mais importantes. Ao invés disso, verifica-se, dada a mutação da realidade, das forças e dos interesses que a compõem, como essencial a permanente fundamentação a fim de contribuir para o seu dinamismo e atualização.

Ratificar a compreensão dos fundamentos da democracia e dos seus instrumentos é fundamental para a sua legitimidade. $\mathrm{O}$ atual sistema de representação e participação da R. Fac. Dir. UFG, v. 40, n.2, p. 47 - 62, jul. / dez. 2016 
coletividade evidencia um conjunto de falhas responsáveis pelo rompimento das relações mais importantes entre a população, as instituições e os governos. Uma dinâmica social com esses limites contribui negativamente para a construção e afirmação de uma comunidade aberta e dinâmica, impedindo as condições de justiça que precisam ser efetivadas e alcançar o cotidiano dos cidadãos. Repensar o processo de participação supõe a opção por uma relação intersubjetiva em vista de uma composição social com condições de impulsionar um processo participativo pleno.

O debate proposto provoca a discussão sobre a concepção de intersubjetividade participativa explicitando a busca pela harmonização entre participação e deliberação popular. A democracia tem entre suas características mais importantes a alternância no exercício do poder e a participação dos cidadãos. Esses são valores que denotam maturidade social e a iminente capacidade de congregar e representar os interesses e as aspirações que, por vezes, se complementam e, em outras situações, são contraditórias. Esse dinamismo é o exercício da intersubjetividade participativa que consolida e ratifica a ordem democrática. Ancorados na ordem constitucional e provocando a construção de mecanismos e estratégias de participação, o cidadão demonstra as condições e a capacidade de influenciar nos destinos da sociedade, promovendo, assim, a ordem social.

O ordenamento constitucional como uma referência irrenunciável das democracias contemporâneas e a participação popular configura o sentido axiológico-efetivo do sistema. As garantias de participação, não apenas formais, mas, especialmente, efetivas, concretizam os valores da solidariedade, da alteridade e da responsabilidade social. Essas são diretrizes e constatações que caracterizam formas participativas conscientes.

O exercício dos direitos e as garantias fundamentais estão inseridos na dinâmica das condições essenciais de justiça. A participação social supõe a compreensão da necessidade de proteção dos direitos tanto individuais quanto coletivos. Assegura-se, assim, a eficácia do processo democrático participativo-deliberativo. Uma sociedade democrática dinâmica e com forte participação social está em permanente adequação, ao mesmo tempo em que permite e dialoga com os movimentos sociais. Esses, por sua vez, legitimam-se como instrumentos comunitários de deliberação e impulsionadores da permanente reestruturação das relações sociais. O espaço público, em permanente tensão, adaptação e transformação, busca a inserção dos movimentos e das demandas sociais, assim como, atualizar as suas instituições e organizações. 
Os movimentos sociais com suas preocupações específicas demonstram a evolução das relações sociais e a reconfiguração do próprio espaço público. A análise indica para a necessidade de inclusão de outras formas de participação e deliberação com condições de aprimorar a democracia. Promover a emancipação social fomentando a expressão das necessidades sociais e dos novos atores demanda formas alternativas de regulação do ordenamento social e as condições para a atuação democrática desses movimentos. Uma democracia efetiva e dinâmica não despreza ou menospreza os movimentos sociais.

\section{INTERSUBJETIVIDADE E PARTICIPAÇÃO}

Por mais expressiva que seja a perspectiva da soberania popular participativa e da participação em geral, há de se convir que se penetra na dificuldade de se construir/desenvolver uma teoria crítica, entendendo-se essa como toda a teoria que não reduz a "realidade" ao que existe (SANTOS, 2007, p. 23). A teoria da participação, mais especificamente, da intersubjetividade participativa $^{1}$, tem feridas não cicatrizadas formadas a partir da herança moderna. A dependência a um traçado de racionalidade que determina heteronomamente as pessoas, na concepção de Warat (1997, p. 12), demonstra a complexidade em se firmar a participação consciente como perspectiva vinculada à sociedade, e sua necessidade - não atual - de quebrar seus paradigmas individuais, senão, individualistas.

A modernidade - para além de promessas - confundiu ao mesmo tempo em que transformou as características de inserção e entendimento sobre o individuo e do modo como seria sua expressividade em relação às liberdades (promessa marcantemente moderna). A questão da liberdade individual pode ensejar o alargamento da impotência coletiva (BAUMAN, 2000, p. 10), na medida em que as ligações entre o público e o privado não são ponderáveis, ou pela evidência de constante transformação e novas invenções das criações (pós)modernas, o que não permite que seja construída a interação entre o público e o privado. Com efeito, as instituições, os organismos sociais, as construções coletivas “não podem mais manter sua forma por muito tempo, pois se decompõem e se dissolvem mais rápido que o tempo que leva para moldá-las e, uma vez reorganizadas, para que se estabeleçam” (BAUMAN, 2007, p. 7). Eis a herança líquida ${ }^{2}$ moderna.

Para dar consistência à expectativa das iniciativas e da consciência do coletivo, a emancipação social deve estar imbuída de um processo participativo. Em continuidade, faz-se necessária a criação de uma nova deliberação social e política, somando à cidadania tanto na R. Fac. Dir. UFG, v. 40, n.2, p. 47 - 62, jul. / dez. 2016 
obrigação política vertical entre os cidadãos e o Estado, como na obrigação política horizontal entre cidadãos (SANTOS, 2005, p. 279). De forma mais específica, a participação é o que provoca a possibilidade da emancipação social, buscando nos referenciais coletivos fraternos a efetivação dos direitos e projeções da sociedade.

É nesse sentido que se busca um âmbito social, político e, também, jurídico acessível de forma ampla, para que a projeção da participação possa se desenvolver segundo uma especificidade de interpretação cidadã, partes interligadas entre os grupos coletivos e que fomentam as expectativas da intersubjetividade participativa, ou seja, dando capacidade para que exista uma tangível compreensão do contexto vivido entre o público e o privado e o lugar comum entre ambos, por ser parte da estrutura social e de sua dinâmica de transformação/evolução. Com isso, a intersubjetividade passa a ser a interação proveniente a partir das relações sociais e que cria estruturas consistentes de participação e reformulação(ções) democrática(s). A referência ao político é mensurável, pois a construção democrática depende da deliberação entre os cidadãos participantes do projeto democrático e as entidades representativas, e jurídico, em que ocorrendo lacunas entre o efetivado pela entidade representativa em relação às projeções sociais, é o acesso ao jurídico - mais em específico, acesso à justiça - que, com o auxílio de outros instrumentos de manutenção e proteção dos direitos sociais, relatam um contexto de ponderação entre a Constituição e as lacunas do necessário e do realizado ${ }^{3}$.

Nessa conjuntura, o princípio comunitário da interpretação constitucional, possibilitador da participação consciente (o ser-aí democrático), assegura ao meio comunitário a utilização de vários e novos institutos, que garantem a capacidade para se desenvolver processos de controle, principalmente jurídicos (CITTADINO, 2004, p. 49). O controle judicial reflete uma cidadania juridicamente participativa, que se justifica por meio das garantias processuais constitucionais, visto que confere prioridade aos temas de igualdade e dignidade da pessoa humana, alterando um âmbito jurídico contemporâneo preocupado unicamente em dirimir interesses individuais (patrimonialistas) para um âmbito de projeções que envolvam interesses coletivos (CITTADINO, 2004, p. 72). Assim, transcende-se a exclusiva percepção individual para uma interação comunitária de interesses intersubjetivos.

A intersubjetividade participativa qualifica-se como meio de exercício democrático, pois, por meio da (inter)participação dos cidadãos sob a qualificação de intérpretes do binômio público-privado, o acesso aos meios garantidores de seus direitos, poderá instaurar um processo 
verdadeiramente emancipatório, lutando contra mecanismos de reprodução das desigualdades e o velamento das diferenças.

\section{DELIBERAÇÃO POPULAR E (NOVOS) ARRANJOS DEMOCRÁTICOS}

As inúmeras formas de participação que os cidadãos, os movimentos sociais, as associações, as instituições e outras organizações dispõem para influenciar os destinos da sociedade representam, tanto do ponto de vista simbólico quanto da sua funcionalidade, mecanismos decisivos para a que a arquitetura da sociedade expresse o conjunto de necessidades, aspirações, dinâmicas e perspectivas existentes no seu interior no presente e em relação ao futuro. A caracterização de sujeito de direito conquistada pelas democracias mais evoluídas tem como correspondência imediata a necessidade de condições reais de participação na dinâmica de estruturação justa da sociedade. Sem a referida caracterização para a expressão da vontade e dos anseios dos cidadãos os demais valores democráticos perdem suas referências, assim como, as instituições o seu dinamismo.

A deliberação se insere no âmbito da participação no momento em que se tem clara a ideia de que os meios participativos possuem manutenção e continuidade por meio de diversos atos argumentativos coletivos. Tal argumentação representa o viés político da participação orientada por uma ação determinada pela compreensão e vinculação à esfera coletiva (BARBER, 1984, p. 155). Os procedimentos participativos orientados pela deliberação constroem a noção do social como engajamento conjunto, coletivo. Os meios participativos possuem a instância de criação e discussão do bem comum, unindo os diversos grupos sociais em torno de aspectos comuns, sancionando o princípio da comunidade (PEREIRA, 2007, p. 430).

Deve-se, para tanto, ampliar os espaços de participação, não só em nível de instrumentos de participação, mas de forma que as bases que inserem os indivíduos na participação sejam oriundas de mecanismos deliberativos, definindo as prioridades dos grupos sociais (Idem, p. 438). A participação deliberativa proposta é, segundo Young (2001, p. 365386) - a qual idealiza a democracia como processo criador do público -, a que possibilita a emergência de cidadãos conjuntamente decidindo objetivos em comum. A alternativa é que "os processo democráticos são orientados em torno da discussão do bem público, ao invés de

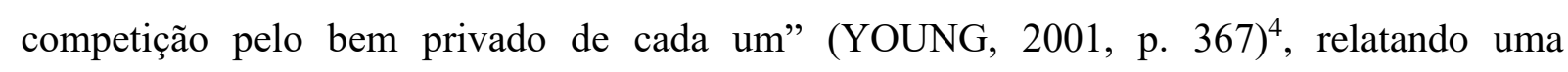
participação deliberativa. A problemática levantada pela autora é que as democracias hodiernas R. Fac. Dir. UFG, v. 40, n.2, p. 47 - 62, jul. / dez. 2016 
não acorçoam os processos deliberativos e originam uma orientação consumidor-privatizada em relação aos cidadãos (Idem, p. 368). A proposta de Young (2001) é de que a participação seja determinada por um referencial comunicativo, do qual chama de "democracia comunicativa”, na qual existe um ideal mais inclusivo, visto que o diálogo político propende a solucionar problemas coletivos com uma variedade de expectativas a cada particularidade social (Idem, p. 386).

Participação e deliberação possuem espaços abrangentes que se complementam na medida em que a participação requer meios deliberativos para sua efetivação. Nesse prisma, uma participação ativa resulta em condições de diálogo entre as particularidades sociais, o qual trabalha em função da deliberação enquanto norteador do procedimento democrático.

\section{O FOMENTO À PARTICIPAÇÃO POPULAR}

O fomento à participação popular parte da compreensão de que a participação dos grupos de interesses, conforme aduz Silva (2003, p. 15), é uma condição para evitar a tirania das elites, bem como um procedimento de controle contra o despotismo dos próprios grupos de interesse. A importância da participação está coesa com o imperativo do grupo de interesse em mobilizar recursos de capacidade e de participar com vantagens do mercado e da inserção ao público. Assim, a eficácia da participação popular, no aspecto de inclusão ou manutenção de processos de exclusão nos centros decisórios, está delimitada pelo mérito do indivíduo em desenvolver suas capacidades e em aproveitar as oportunidades oferecidas pelo sistema sóciopolítico. Contudo, tal mérito está intrinsecamente vinculado à possibilidade de inserção aos meios participativos.

Como aduz Toro (2005, p. 29), “a democracia é para todos e para ela" - enquanto sistema que provoca o coletivo -, sendo o público aquilo que convém a todos. O público é mais amplo e transcende o Estado, sem que isso signifique desconhecer que as instituições públicas por excelência devem ser o Estado e as leis, precisamente porque a força do público vem de sua capacidade de sintetizar e representar os interesses, contraditórios ou não, de todos os setores da sociedade (HERRERA, 1992, p. 14). O fomento à participação popular justifica-se justamente pela inclusão dos titulares participativos na capacidade de sintetizar e garantir os interesses dos setores da sociedade no aspecto de uma intersubjetividade social participativa. Toro (2005) registra que a democracia deve estar embasada em princípios de ordem ética, que fazem parte do processo democrático diretamente. Pelo princípio da secularidade, a ordem 
social não é natural, mas passível de transformações. Percebe-se, pois, que os cidadãos são fonte e criadores dessa ordem, podendo modificá-la. O princípio da autofundação, determina que a democracia é um ato decisório da sociedade e só pode emergir de um acordo mútuo e do cumprimento e respeito àquilo que partiu de iniciativa livre e coletiva, a autofundação somente é possível com a intersubjetividade social participativa. O princípio da incerteza ratifica a democracia não como modelo, mas como uma forma específica de cada sociedade, em harmonia à sua ordem social. Pelo princípio da complexidade, característica evidente da democracia, o conflito e a diversidade são elementos constitutivos da democracia. Por fim, e que de certa forma abrange todos os princípios, há princípio do público, que, segundo o autor, se constrói na sociedade civil. Para tanto, somente quando o grupo social delibera coletivamente sobre a construção de suas instituições com fundamento na dignidade da pessoa humana é que a democracia perdurará (Idem, p. 29).

\section{OS MOVIMENTOS SOCIAIS COMO CONFIGURAÇÕES PARA LEGITIMAR DELIBERAÇÕES}

A configuração do acelerado processo de globalização não impediu o surgimento de novos movimentos sociais mais abrangentes e de repercussão global. Pode-se perceber, também, a afirmação de outros em nível local ou nacional com repercussão menos restrita ou mesmo universal. O surgimento dos movimentos sociais ocorre fora dos espaços institucionais controlados pelo Estado. Propor formas de integração com o Estado ou meios de relacionamento entre esses, altera substancialmente o objetivo e a identidade de ambos os atores, considerando seus objetivos e métodos de atuação. Essa reflexão debate a possibilidade de construir uma relação de não submissão que resguarda a identidade social ao mesmo tempo em que permite maior legitimidade às decisões do Estado. $\mathrm{O}$ atendimento das necessidades da sociedade é fundamental para o equilíbrio das relações sociais. Para tanto, o surgimento e fortalecimento dos movimentos sociais é um imperativo que garante a expressão da realidade social, a denúncia das limitações do Estado e a apresentação das demandas mais urgentes.

A inovação de uma relação intersubjetiva participativa está na possibilidade de retirar as barreiras da regulação a fim de originar a efetiva emancipação social. As necessidades sociais, quando evidenciadas pela dinâmica dos movimentos sociais têm condições de serem atendidas e as decisões do Estado obterem maior legitimidade. Segundo Boaventura de Sousa Santos (2005, p. 69), experiências de alteração nas estruturas democráticas se originaram por 
meio de movimentos sociais, os quais partem da quebra de um senso comum em relação às práticas sociais de exclusão, conduzindo a geração de novas normas e participações na governabilidade. Santos (2007, p. 61-62) destaca as mazelas que caracterizam a atuação dos movimentos sociais que, em certas ocasiões, conduzem ao ceticismo e outras dificuldades que impedem a consolidação dos projetos democráticos. Essa problemática, dependendo da realidade social interpretada, está inserida na distinção de seis espaços estruturais, os quais geram seis formas distintas de poder: o espaço-tempo doméstico, que reflete o poder patriarcado; o espaço-tempo da produção, centrado na exploração; o espaço-tempo da comunidade, evidenciando a diferenciação comunitária desigual; o espaço-tempo do mercado, em que o poder é o encantamento pelas mercadorias; o espaço tempo da cidadania (espaço público), no qual o poder é a dominação gerada pela solidariedade vertical entre cidadãos e Estado (Idem, p. 61-62).

Os movimentos sociais têm o poder de romper práticas e concepções em diferentes âmbitos fundamentais do ordenamento social. Ao alterar, politizar e criar alternativas para as esferas sociais modifica a identidade dos atores sociais. Quanto mais expressiva a atuação dos movimentos sociais, menos limitada será a sociedade e sua organização, especificamente, a legislação e as instituições.

Essa dinâmica aduz a construção de um novo paradigma no qual, conforme atesta Goss (2004, p. 78-79), “a posição que o sujeito assuma nas relações de produção não determina necessariamente suas demais posições; não é mais possível determinar a realidade por meio de estágios que apareceriam em sucessivas fases do desenvolvimento da sociedade", ou seja, "o político é uma dimensão presente em toda prática social não em um espaço específico" (Idem, p. 79). As concepções políticas fechadas são redimensionadas em vista da efetivação de espaços em permanente transformação e (re)formulação.

As posturas dos movimentos sociais possuem, normalmente, características e posturas relacionadas à reivindicação, contestação e desejo de maior participação. As reivindicações se dirigem ao Estado, dada sua ineficiência na garantia dos direitos fundamentais e na postulação de melhores condições de vida; diante da carência material acentua-se a ação contestatória de oposição ao poder vigente o desejo de maior participação para o desenvolvimento e a construção da democracia fortalece a demanda participativa, esta sustenta e desenvolve com mais intensidade os movimentos sociais. A participação popular reforça atuação visando uma relação com o Estado menos institucionalizada (VÉRAS e BONDUKI, 1988, p. 68-69). 
A legitimação e a defesa coletiva dos direitos sociais têm como referência os novos movimentos sociais visto que ratificam e legitimam o desejo e os mecanismos de participação. Novos, em função da constante (re)articulação do espaço público. $\mathrm{O}$ fomento à participação permite que os cidadãos integrem a comunidade política na condição de agentes e interajam entre o público e o privado. Os cidadãos participam ativamente do processo de deliberação dos seus direitos básicos, assim como, das demandas do cotidiano.

\section{PARTICIPAÇÃO INTERSUBJETIVA E PROJEÇÕES DEMOCRÁTICAS}

A participação na sociedade com suas diversas instituições, associações, partidos e demais instâncias e sua ampliação conforme a dinâmica do contexto social é possível somente naquelas que assumem a democracia como o sistema orientador de sua organização. Essa é uma característica possível e pertinente a todas as sociedades independente de pré-condições.

A democracia está diretamente relacionada à efetivação de amplos mecanismos de participação, sendo esta, a condição indispensável para a sua evolução e atualização permanentes. Sabendo que sem democracia não se pode falar ou fundamentar um modelo de desenvolvimento adequado, nas ultimas décadas caracterizado como sustentável, a consequência imediata é afirmar que a participação é um processo necessário e adequado para a sua legitimidade moral. As garantias legais, presentes na Constituição Federal e respaldada pelas convicções do conjunto da população, concluem o processo de relacionamento intersubjetivo com as condições efetivas de demonstrar o vigor de uma comunidade e do seu povo.

Uma sociedade bem ordenada, nos parâmetros da democracia, compreende um núcleo de sustentação de valores, princípios e instituições que garantem a sua estabilidade política e a correção de suas deficiências. O esclarecimento desse referencial é indispensável para a sua sustentação e efetivação no cotidiano da população. Esclarece Cardoso (2010, p. 125):

\footnotetext{
Uma democracia só é verdadeiramente substantiva quando está enraizada na sociedade e é alimentada por uma sociedade civil vibrante e por uma cultura cívica de participação, responsabilidade e debate. Esta é a razão pela qual a democracia é sempre, uma obra em curso, uma construção inacabada. Trata-se de um processo que deita raízes na história e na cultura de cada sociedade. Por esta razão não pode ser imposta de fora para dentro e nunca está definitivamente assegurada.
}

Em uma dinâmica de crescente participação que envolve o conjunto da população formata-se, além de um modelo de estruturação social, a identidade dos seus membros. Nesse R. Fac. Dir. UFG, v. 40, n.2, p. 47 - 62, jul. / dez. 2016 
caso, especificamente, deve-se afirmar a característica cunhada na Constituição Brasileira quando entende cada cidadão como sujeito de direitos.

Uma democracia que tem esse nível de compreensão em relação aos seus membros antecipa sua disposição de superação das desigualdades que ameaçam as condições de justiça com a integração das pessoas em um processo permanente de participação e valorização. Sociedades autoritárias ou com democracias frágeis, dominadas por ditaduras ou com atuação de mercados não regulamentados, preocupam-se, prioritariamente, quando não exclusivamente, com o cumprimento dos deveres impostos sem o conhecimento e a adesão da população.

Pode-se observar a contradição, ao mesmo tempo, política, pedagógica e legislativa. O impedimento da participação nega os fundamentos da democracia e despersonaliza o cidadão. A importância de concretizar a intersubjetividade participativa evidencia a necessidade de a legislação permitir, ordenar e fomentar as manifestações livres dos cidadãos com seus inúmeros métodos e organizações. Essa não representa uma contradição em relação à identidade do Estado ou a tendência dos governantes serem avessos às manifestações populares porque demonstram os limites ou a incapacidade dos dirigentes de solucionar seus problemas. Ao contrário, dispõem de espaços de diálogo e expressão livre. Essa é uma relação tensa e construtiva que dinamiza e fortalece as relações sociais, concretizando a democracia e os meios de participação conjunta.

A avaliação da identidade do cidadão, da sua participação e do seu compromisso com o futuro não se restringem às condições previamente elaboradas, especialmente, às condições de bem-estar ou estatísticas, mas a sua condição de agente ativo na sociedade, conforme esclarece Sen (2000, p. 221):

\footnotetext{
E, no entanto, não podem deixar de ser diferentes em nível básico, pois o papel de uma pessoa como "agente" é fundamentalmente distinto do papel dessa pessoa como "paciente" (embora não independente desse ultimo papel). $\mathrm{O}$ fato de que o agente pode ter de ver a si mesmo como paciente não altera as modalidades e as responsabilidades adicionais inevitavelmente associadas à condição e agente das pessoas.

Ver os indivíduos como entidades e agentes que sentem e têm bem-estar é um reconhecimento importante, mas ficar só nisso implica uma concepção muito restrita da mulher como pessoa. Portanto, compreender o papel da condição de agente é essencial para reconhecer os indivíduos como pessoas responsáveis: nós não estamos apenas sãos ou enfermos, mas também agimos ou nos recusamos a agir, e podemos optar por agir de um modo e não de outro.
}

A condição de agente das pessoas influencia e dinamiza o conjunto da sociedade e implica, além da ampliação das condições de vida material, o desenvolvimento de um conjunto de dimensões individuais, comunitárias, institucionais e sociais que, conjuntamente, atuam e 
contribuem para o equilíbrio social e ratificam a condição de sujeito de direitos. Ambas são caras e indispensáveis para a democracia e o aprimoramento dos mecanismos de participação.

A ampliação e o fomento à participação efetiva e confirma a importância das garantias para o exercício da liberdade e como um valor intrínseco que integra a razão pública de uma sociedade democrática. Nessa abordagem que integra a necessidade de explicitar e ampliar o exercício da intersubjetividade participativa como uma resposta privilegiada para a articulação entre a atuação do Estado, os movimentos sociais e as demais formas de representação individual e coletiva, a liberdade afirma-se como um valor moral substantivo (ZAMBAM, 2012, p. 49). A ausência de liberdade tem como consequência direta a instalação de situações de injustiça social. Assumir o seu valor moral substantivo é situá-la como condição para a estruturação e avaliação do conjunto da arquitetura social, especificamente, as condições e mecanismos de participação, as políticas de desenvolvimento, a atuação das instituições jurídicas, a efetivação das condições de justiça, a garantia dos direitos sociais fundamentais, a liberdade de expressão e informação e as formas de representação.

A compreensão da intersubjetividade participativa realça que as manifestações da diversidade constitutiva das sociedades democráticas em todas as suas expressões é fundamental para a construção da justiça. O exercício permanente da crítica e a construção de relações plurais, normalmente tensas e de difícil acordo, fortalecem a liberdade, afirma as instituições, dinamizam o conjunto das representações sociais e incentiva a construção de novos instrumentos para expressar livremente a vontade geral.

O Estado, por sua vez, atualiza suas formas de atuação e seu aparelho de relacionamento com a sociedade. As instituições, especificamente as garantidoras da justiça formal, precisam responder às demandas da sociedade com a mesma intensidade que são provocadas e dinamizar sua ação mudando seus métodos de relacionamento e julgamento. Uma relação pautada pela intersubjetividade participativa tem como prerrogativa básica a capacidade de dialogar e atualizar a sua atuação propondo e materializando ações capazes de evidenciar as condições de justiça.

\section{CONCLUSÃO}

A eleição da Constituição Brasileira de 1988 como uma carta cidadã implica uma permanente interação entre o extrato legal, o contexto social e a atuação de cada cidadão como sujeito de direitos. Essa afirmação supõe uma interação permanente, direta e representativa, das R. Fac. Dir. UFG, v. 40, n.2, p. 47 - 62, jul. / dez. 2016 
necessidades, das demandas e objetivos da sociedade. Entretanto, constatam-se inúmeras deficiências quanto ao grau de legitimidade do exercício participativo, demonstrando o afastamento entre os diversos setores sociais, titulares privilegiados da participação, e a construção do processo democrático. Propor a intersubjetividade participativa visa compor uma relação que conjuga, simultaneamente, a participação e a deliberação.

A dinâmica existente na sociedade brasileira expressa o contingente de interesses presentes no seu interior e a exigência de novas formas de participação e interação dos cidadãos e das instituições com o Estado e, desse, com o atendimento das demandas da população e o ordenamento equitativo da administração dos recursos disponíveis.

A atuação dos cidadãos não se limita ao atendimento de interesses corporativos, institucionais ou pautados por metas que buscam a satisfação individual, ou mesmo, do Estado e seus dirigentes. Na condição de agente, o homem, constrói sua autonomia e age na sociedade. A realização humana independe de condições previamente estabelecidas ou de políticas limitadas à avaliação das condições de bem-estar social ou pautadas pela dependência da atuação do Estado. Sujeito é o cidadão que participa ativamente da sociedade e dos seus destinos, desenvolve suas capacidades, faz as suas escolhas livremente, atua nas diferentes instâncias, especialmente nos âmbitos dos movimentos sociais e influencia na organização do presente e nas condições de existência futuras, assim como, nas políticas de desenvolvimento sustentável, o que prioriza uma sociedade justa, equitativa e democrática.

As sociedades que pautam a sua organização e funcionamento pelas orientações democráticas não temem os movimentos sociais. Esses, cujas manifestações estão previstas no texto constitucional, são instrumentos efetivos de participação. O Brasil inúmeras vezes limitou esse espaço privilegiado de atuação e deliberação social, seja por governos ditatoriais ou por interesses corporativos. Atualmente, percebem-se inúmeras formas de cooptação dos movimentos sociais por interesses de quem detém o poder, reduzindo as suas organizações ao exercício da retórica política que interessa aos dirigentes de agremiações políticas ou de corporações econômico-financeiras. Embora não impeça a organização de movimentos sociais, tal estratégia limita a dinamização da democracia e a emancipação da sociedade.

A instrumentalização da democracia por interesses político-partidários ou de marcado é tão ameaçadora quanto à apropriação dos recursos e instituições do Estado por governos autoritários. Aqueles chamados a decidir e interagir no âmbito social (sem esquecer do político) precisam ter garantidos os direitos de exercer a liberdade de expressão, reunião, 
associação, acesso às informações, não apenas no dispositivo constitucional, mas como uma característica própria da intersubjetividade participativa.

Assim, pensar a intersubjetividade participativa é compreender e exercitar essa dinâmica de participação social que tem como meta a formação do cidadão integrado de forma plena e ativa nas múltiplas instâncias da sociedade e atuando para estabelecer os espaços de diálogo sociais que ampliam uma ação para além do individual ou corporativo para o fortalecimento dos espaços que evidenciam os interesses e as necessidades coletivas.

Tão importante quanto à habilitação dos sujeitos representativos é o reconhecimento de sua legitimidade e as condições de fazê-lo com a coerência e a sabedoria política necessárias. As novas formas de atuação e representação social demandam um relacionamento social atualizado, lendo-se atualizado como a possibilidade de que a partir da sociedade formem-se frentes de participação e deliberação na formação do espaço público democrático.

\section{REFERÊNCIAS}

BARBER, B. R. Strong Democracy - participatory politics for a new age. Barkeley: University of California Press, 1984.

BAUMAN, Z. Em busca da política. Tradução Marcus Penchel. Rio de Janeiro: Jorge Zahar, 2000. 2007.

Tempos líquidos. Tradução Carlos Alberto Medeiros. Rio de Janeiro: Jorge Zahar,

CARDOSO, F. H. Xadrez internacional e social-democracia. São Paulo: Paz e terra, 2010.

CITTADINO, G. Pluralismo, direito e justiça distributiva, elementos da filosofia constitucional contemporânea. 2. ed. Rio de Janeiro: Lúmen Juris, 2004.

GOSS, K. P.; PRUDENCIO, K. O conceito de movimentos sociais revisitado. Revista Eletrônica dos Pós-graduados em Sociologia Política da UFSC. vol. 2. n. 1. (Janeiro-Julho 2004). Florianópolis, 2004, disponível em http://www.emtese.ufsc.br/n2.htm, acesso em 06 de outubro de 2015.

HERRERA, D. La democracia: una verdad y un valor éticos en construcción. In.: Soberania popular y democracia en Colombia. Bogotá: Ediciones Foro Nacional por Colombia y Viva la Ciudadania, 1992. 
PEREIRA, M. A. Modelos democráticos deliberativos e participativos - similitudes, diferenças e desafios. In.: DAGNINO, E.; TATAGIBA, L. (orgs.). Democracia, sociedade civil e participação. Chapecó: Argos, 2007.

SANTOS, Boaventura de Sousa. A crítica da razão indolente: contra o desperdício da experiência. Para um novo senso comum. A ciência, o direito e a política na transição paradigmática. Vol. 01. 6. ed. São Paulo: Cortez, 2007.

2005 .

Pela mão de Alice: o social e o político na pós-modernidade. 10. ed. São Paulo: Cortez,

Renovar a teoria crítica e reinventar a emancipação social. Tradução Mouzar Benedito. São Paulo: Boitempo, 2007.

SEN, Amartya. Desenvolvimento como liberdade. 3. ed. Tradução Laura Teixeira Motta. São Paulo: Companhia das letras, 2000.

SILVA, I. G. Democracia e participação na "reforma” do Estado. São Paulo: Cortez, 2003.

SOUZA, J. T. B. Ética como metafísica da alteridade em Levinas. Tese de doutoramento. Programa de Pós-graduação em Filosofia. PUC/RS, 2007.

TORO, J. B. A construção do público: cidadania, democracia e participação. Rio de Janeiro: Senac Rio, 2005.

VÉRAS, M.; BONDUKI, G. Política habitacional e a luta pelo direito à habitação. In.: COVRE, M. L. (org.). A cidadania que não temos. São Paulo: Brasiliense, 1988.

WARAT, L. A. Introdução geral ao direito. O direito não estudado pela teoria jurídica moderna. Vol. III. Porto Alegre: Sergio Antonio Fabris Editor, 1997.

YOUNG, I. M. Comunicação e o outro: além da democracia deliberativa. In.: SOUZA, J. (org.). Democracia hoje: novos desafios para a teoria democrática contemporânea. Brasília: Editora Universidade de Brasília, 2001.

ZAMBAM, N. Amartya Sen: liberdade, justiça e desenvolvimento sustentável. Passo Fundo: Imed, 2012.

\footnotetext{
${ }^{1}$ Intersubjetividade, para efeitos do presente artigo, corrobora com a ideia de SOUZA, ao afirmar, com embasamento em Husserl e Levinas, que se "descobre o outro, que também é um eu, que tem suas pertenças próprias, e também pode configurar o sentido de objetividade. Aparece, assim, a iminência da constituição real ser produzida de modo intersubjetivo, ou seja, a possibilidade de objeto ser construído numa 'unidade de intencionalidade intersubjetiva'. Em vez do ego, eu solitário, emerge um 'nós', constituinte. A intencionalidade configura-se como intencionalidade intersubjetiva". (2007. p. 73)

2 "Líquida" é a terminologia utilizada por Zygmunt Bauman para caracterizar as transformações constantes oriundas da modernidade. Vide BAUMAN, 2007.

${ }^{3}$ É, por tanto, pela via da participação político-jurídica, aqui traduzida como o alargamento do círculo de intérpretes da constituição, que se processa a interligação entre os direitos fundamentais e a democracia participativa. Em outras palavras, a abertura constitucional permite que cidadãos, partidos políticos, associações
} 
etc., integrem o círculo de interpretes da constituição, democratizando o processo interpretativo - na medida em que ele se torna aberto e público - e, ao mesmo tempo concretizando a constituição. Idem, 2004. p. 19.

${ }^{4}$ Em vez de raciocinar do ponto de vista maximizado da utilidade privada, os cidadãos transformam, por meio da deliberação pública, suas preferências, de acordo com fins de ordem pública, raciocinando juntos sobre a natureza desses fins e sobre os melhores meios de atingi-los. Num diálogo livre e aberto, outros testam e desafiam as afirmações e os motivos. Os participantes cuidam de separar os bons motivos dos maus e os argumentos válidos dos inválidos. Idem, p. 367.

Artigo recebido em 20 de abril de 2015 e aceito em 30 de junho de 2016 